\title{
Industrial Energy Management During a Pandemic: Lessons Learned from DOE Better Plants Program Partners
}

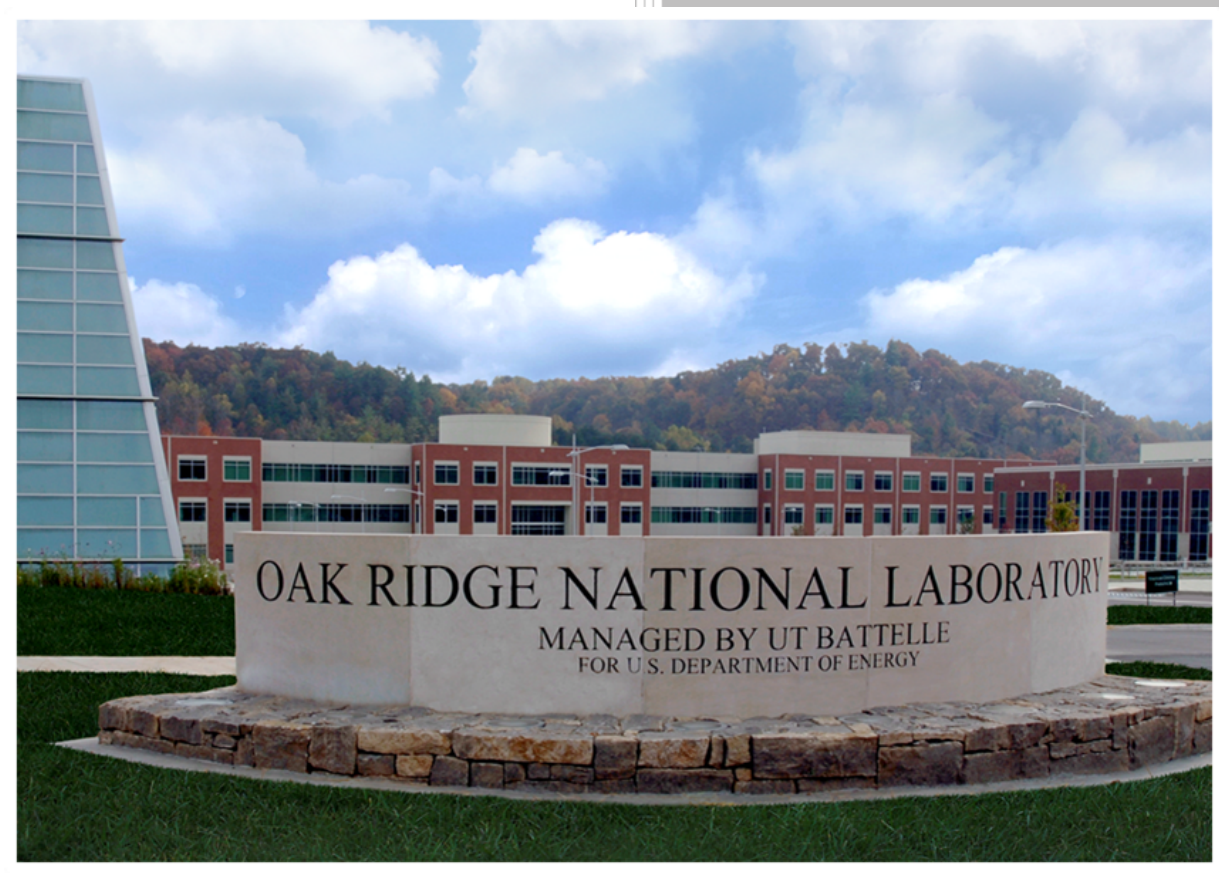

Wei Guo

Thomas Wenning Sachin Nimbalkar

Eli Levine

Bruce Lung

October 2020 


\section{DOCUMENT AVAILABILITY}

Reports produced after January 1, 1996, are generally available free via US Department of Energy (DOE) SciTech Connect.

Website www.osti.gov

Reports produced before January 1, 1996, may be purchased by members of the public from the following source:

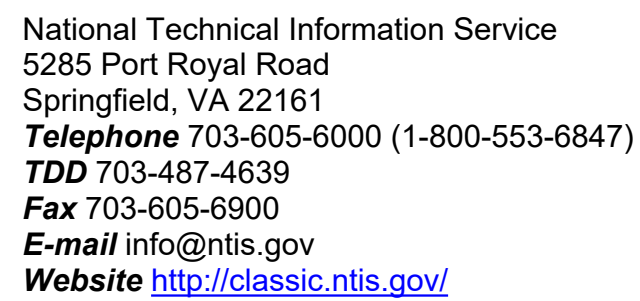

Reports are available to DOE employees, DOE contractors, Energy Technology Data Exchange representatives, and International Nuclear Information System representatives from the following source:

Office of Scientific and Technical Information

PO Box 62

Oak Ridge, TN 37831

Telephone 865-576-8401

Fax 865-576-5728

E-mail reports@osti.gov

Website http://www.osti.gov/contact.html

This report was prepared as an account of work sponsored by an agency of the United States Government. Neither the United States Government nor any agency thereof, nor any of their employees, makes any warranty, express or implied, or assumes any legal liability or responsibility for the accuracy, completeness, or usefulness of any information, apparatus, product, or process disclosed, or represents that its use would not infringe privately owned rights. Reference herein to any specific commercial product, process, or service by trade name, trademark, manufacturer, or otherwise, does not necessarily constitute or imply its endorsement, recommendation, or favoring by the United States Government or any agency thereof. The views and opinions of authors expressed herein do not necessarily state or reflect those of the United States Government or any agency thereof. 
Energy and Transportation Science Division

\title{
INDUSTRIAL ENERGY MANAGEMENT DURING A PANDEMIC: LESSONS LEARNED FROM DOE BETTER PLANTS PROGRAM PARTNERS
}

\author{
Wei Guo (Oak Ridge National Laboratory) \\ Thomas Wenning (Oak Ridge National Laboratory) \\ Sachin Nimbalkar (Oak Ridge National Laboratory) \\ Eli Levine (US Department of Energy) \\ Bruce Lung (Boston Government Services LLC)
}

Date Published: October 2020

Prepared by

OAK RIDGE NATIONAL LABORATORY

Oak Ridge, TN 37831-6283

managed by

UT-BATTELLE, LLC

for the

US DEPARTMENT OF ENERGY

under contract DE-AC05-00OR22725 



\section{CONTENTS}

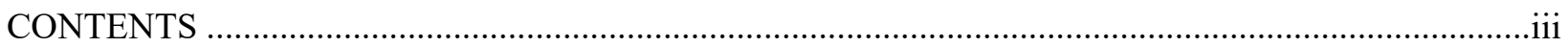

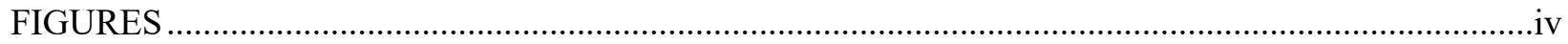

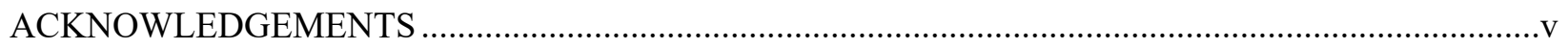

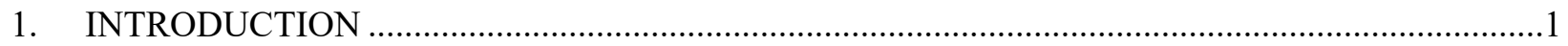

2. CHALLENGES IN INDUSTRIAL ENERGY MANAGEMENT AND POTENTIAL

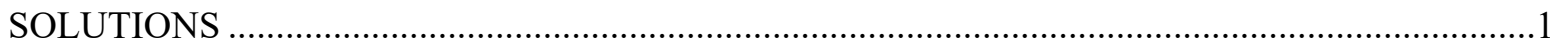

2.1 STRAINED BUDGET FOR ENERGY PROJECTS ....................................................

2.1.1 Solution 1: Implement No- and Low-Cost Energy Conservation Measures ..................2

2.1.2 Solution 2: Adopt Alternative Financing Options ....................................................

2.2 INCREASED ENERGY INTENSITY CAUSED BY LOW PRODUCTION RATE

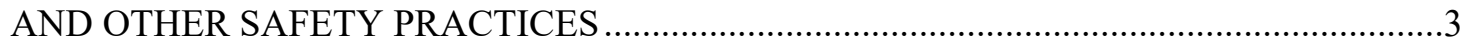

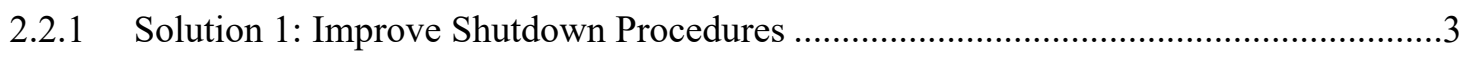

2.2.2 Solution 2: Reduce Baseload Energy ....................................................................

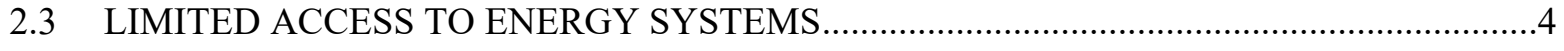

2.3.1 Solution 1: Create an Effective Online Energy-Monitoring System .............................5

2.3.2 Solution 2: Deploy Automatic Predictive Maintenance Technologies ...........................5

2.3.3 Solution 3: Perform Virtual Energy Assessments ..........................................................

2.4 LOST KNOWLEDGE AND EXPERIENCE OF SENIOR STAFF …...................................

2.4.1 Solution 1: Build a Robust Energy-Management System ……....................................

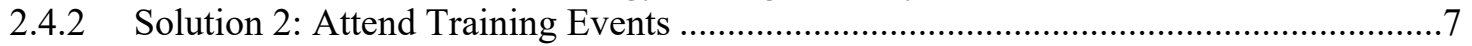

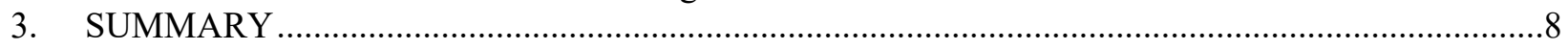

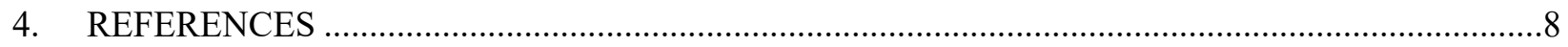




\section{FIGURES}

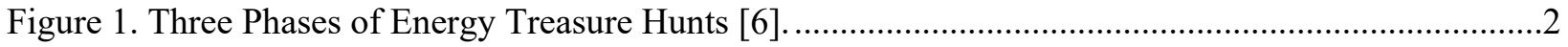

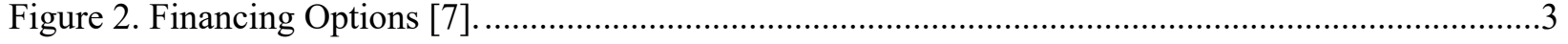

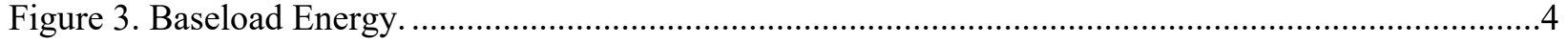

Figure 4. Advanced Air-to-Fuel Ratio Controls [14] ............................................................................6

Figure 5. Energy Management System Model for ISO50001 [17]....................................................... 


\section{ACKNOWLEDGEMENTS}

"Industrial Energy Management During a Pandemic: Lessons Learned from DOE Better Plants Program Partners" was developed for the U.S. Department of Energy's (DOE) Office of Energy Efficiency and Renewable Energy (EERE) as part of the Better Buildings, Better Plants program. The report was developed by staff at Oak Ridge National Laboratory (ORNL) in collaboration with the U.S. Department of Energy. This report was funded by the EERE under Oak Ridge National Laboratory Contract No. DEAC05-00OR22725.

Primary authors for this report are Wei Guo, Thomas Wenning, Sachin Nimbalkar of the Energy and Transportation Science Division, ORNL, Oak Ridge, TN, USA and Eli Levine of the U.S. Department of Energy, Advanced Manufacturing Office, and Bruce Lung of the Boston Government Services (BGS) LLC.

The efforts of the following contributors are appreciated for their review and suggestions for this guidance:

- Mahabir Bhandari, Oak Ridge National Laboratory, Energy and Transportation Science Division

- Jennifer Travis, Oak Ridge National Laboratory, Energy and Transportation Science Division

- Kiran Thirumaran, Oak Ridge National Laboratory, Energy and Transportation Science Division

- Kristina Armstrong, Oak Ridge National Laboratory, Energy and Transportation Science Division

- Christopher Price, Oak Ridge National Laboratory, Energy and Transportation Science Division

- Daryl Cox, Oak Ridge National Laboratory, Energy and Transportation Science Division

- Clifton Yin, ICF International

- Leslie Jones, ICF International

- Kate Rubin, ICF International

- Walt Brockway, Brockway Consulting LLC

- Paul Lemar, Resource Dynamics Corporation 


\section{INTRODUCTION}

Since 2009, more than 235 industrial organizations that represent over 3,000 plants from across the country have set ambitious, long-term energy-reduction goals and agreed to voluntarily join the US Department of Energy's (DOE) Better Plants (BP) Program. Partners agree to join the BP Program for many different reasons: some join for the robust technical assistance, others for the connections to technology and innovation from the DOE National Laboratories, and others still for the recognition and amplification of their leadership. Beyond these important reasons, a key benefit that partners derive is peer-to-peer learning and knowledge sharing. Partners share information about significant energy-saving projects in showcase documents and best practices in implementation models on the Better Buildings Solution Center, present during topical webinars, and participate in accelerators and working groups with like-minded partners. The BP Program convenes its partners several times a year, including during the Better Buildings, Better Plants Summit. Partners enjoy the opportunity to swap stories with other partners, learning about shared challenges and various approaches to overcome them.

Few challenges have been as great as the COVID-19 worldwide pandemic this year. Manufacturers throughout the United States and the world have been trying to understand how to safely open their plants. Some manufacturers shifted production lines to help produce hand sanitizer and personal protective equipment (PPE) in the early months of the pandemic as state governments shut down all nonessential businesses as part of the "Stay at Home" orders. Nearly all manufacturers have had to upend what was "business as usual" to adapt to the new reality. Many significant changes to facility operation and production management have been implemented to ensure workers' safety and production continuity. The dramatic operational changes and economic hardships that companies are experiencing created great challenges for industrial energy management.

In early June 2020, the Better Buildings, Better Plants Virtual Leadership Symposium provided a valuable forum for partners to get together and discuss the challenges they face and what they are seeing both at their plants and on a corporate level. The BP community was also able to make the important connection to sustainability and how the pandemic response will impact plant energy use. Through 15 breakout sessions, the $200+$ participants in the BP industrial meetup shared and brainstormed best practices to mitigate virus transmission and for industrial energy management during the pandemic.

Energy efficiency lowers utility bills, reduces production costs, and enhances competitiveness. Energy efficiency also reduces equipment downtime, extends equipment life, and defers significant investments for new infrastructures to accommodate future production growth. This highlights the importance of industrial energy management for companies to overcome the economic hardship and business uncertainty caused by the pandemic. This paper shares four primary challenges in industrial energy management encountered by BP partners during this pandemic and proposes some potential solutions.

\section{CHALLENGES IN INDUSTRIAL ENERGY MANAGEMENT AND POTENTIAL SOLUTIONS}

\subsection{STRAINED BUDGET FOR ENERGY PROJECTS}

According to a recent survey of the National Association of Manufacturers [1], this pandemic had nearly shut down the economy for some time, and the business recovery speed is still uncertain for many sectors. About $80 \%$ of manufacturers expect that the pandemic will have a negative financial impact on their business. Many companies have adopted more conservative financial policies to face this unprecedented adversity. 
Many significant capital-intensive energy efficiency and renewable energy projects have been suspended. In some cases, the funds originally allocated for energy efficiency projects have been redirected to rearrange facilities and purchase PPE to keep workers safe and follow the guidance from the Centers for Disease Control and Prevention (CDC) and local governments.

\subsubsection{Solution 1: Implement No- and Low-Cost Energy Conservation Measures}

No- and low-cost energy conservation opportunities still exist in most manufacturing facilities. Energy treasure hunts are an effective mechanism for identifying these types of opportunities and increasing employees' energy efficiency awareness. During energy treasure hunts, employees observe an idle and a normal operating day, find equipment that can be turned off or down, and present the findings to the management team on the last day. The average energy savings of opportunities identified during about 25 BP energy treasure hunts was about $7 \%$, and $90 \%$ of these opportunities had less than a 1-year payback.

The BP Program provides in-plant trainings (INPLTs) on energy treasure hunts. Figure 1 shows the three phases of energy treasure hunts. Attendees learn how to facilitate the energy treasure hunt processes, identify energy conservation opportunities, and use the MEASUR tools suite to quantify savings [2]. The Energy Treasure Hunt Toolkit [3], Info Cards (included in Phase 2, Part 2 of the Toolkit), Tip Sheets [4], and source books [5] for various energy systems published by the DOE Advanced Manufacturing Office are good technical resources.

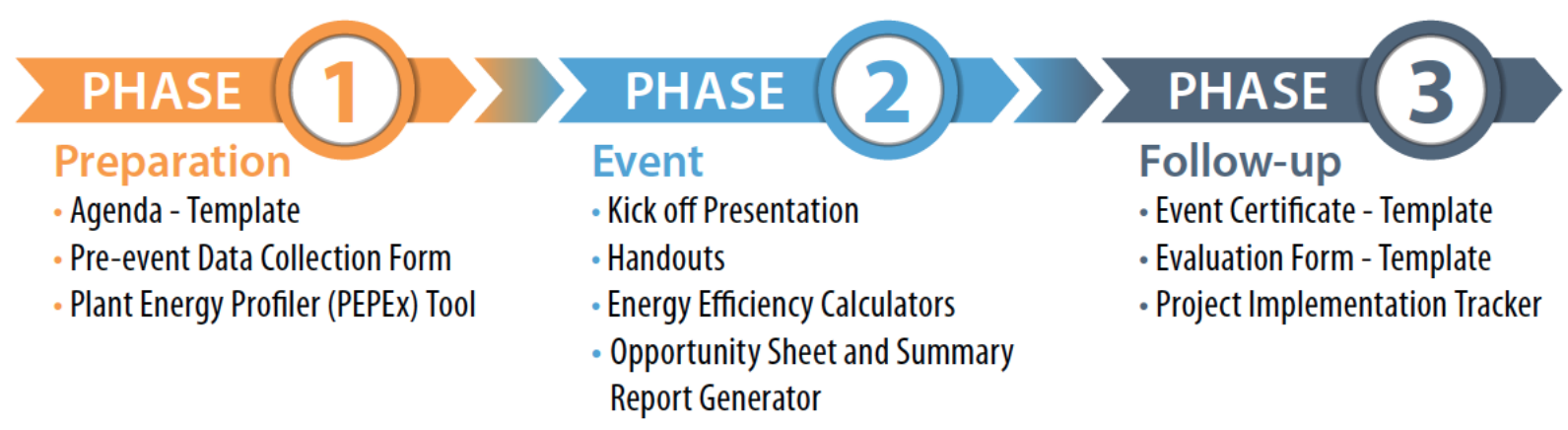

Figure 1. Three Phases of Energy Treasure Hunts [6].

\subsubsection{Solution 2: Adopt Alternative Financing Options}

Many financing options and the companies that provide them are available to work with manufacturing companies to fund energy efficiency and renewable energy projects. The Better Buildings Financing Navigator tool provides great information for traditional and specialized financing [7]. As shown in Figure 2, traditional financing includes capital lease, operational lease, tax-exempt lease, solar lease, commercial loan, below-market loan, and others. Specialized financing includes on-bill financing, on-bill repayment, commercial property assessed clean energy, Energy Savings Performance Contracts (ESPC), Efficiency-As-A-Service (EaaS), and power purchase agreements. More and more companies are using ESPC and EaaS to undertake significant energy projects without upfront capital investment and with minimized performance risk. The Navigator tool also has a list of the Better Buildings Financial Allies who are market-leading financing companies committed to funding energy efficiency and renewable energy projects [8]. 


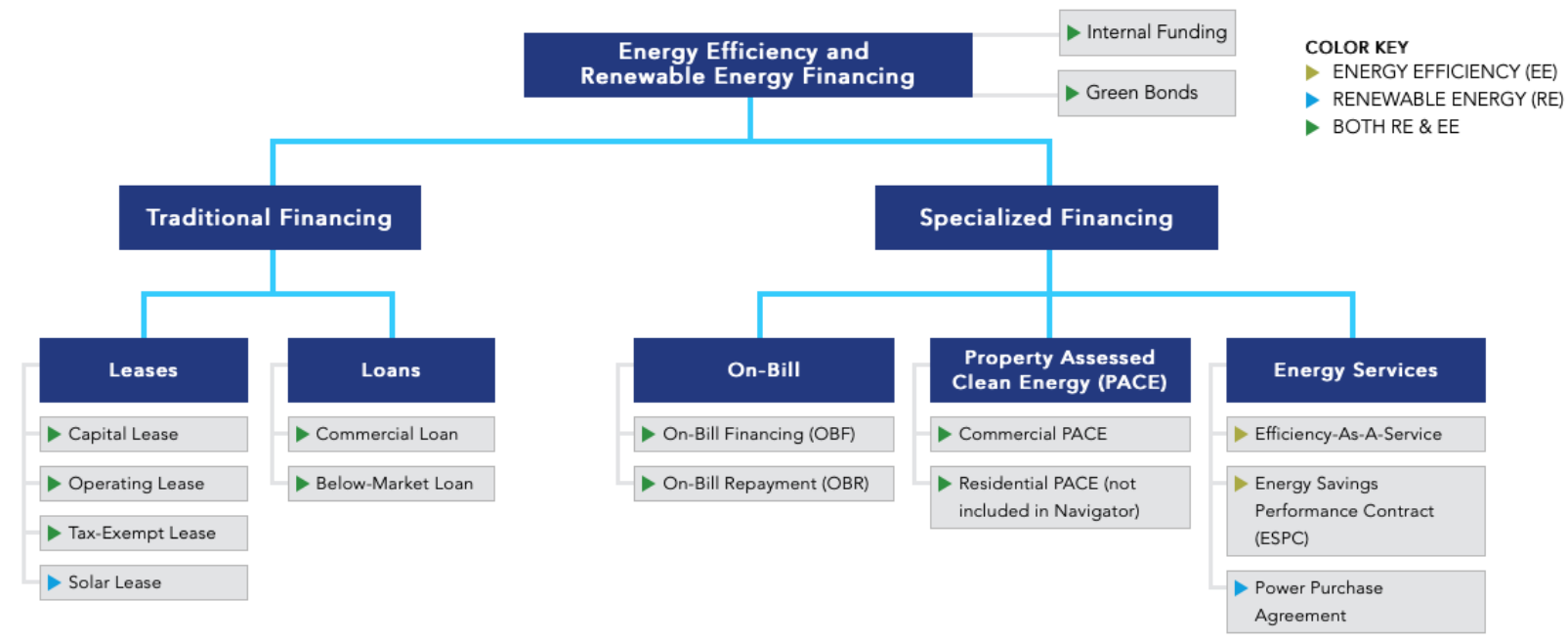

Figure 2. Financing Options [7].

For example, using EaaS, Bentley Mills worked with Redaptive, a Better Buildings Financial Ally, to retrofit the whole facility with high-efficiency LED lighting and domestic water fixtures [9]. The 8-year cumulative energy and water cost savings were estimated to be $\$ 1.5 \mathrm{M}$ and $\$ 73 \mathrm{~K}$, respectively. The actual system performed $10 \%$ better than the original estimate for the first 3 months.

\subsection{INCREASED ENERGY INTENSITY CAUSED BY LOW PRODUCTION RATE AND OTHER SAFETY PRACTICES}

Some companies have been experiencing lower-than-normal production rates due to slowed market demands, but their energy consumption has not been reduced as much as the production rate. Facility energy intensity - the ratio of energy consumption over production rate-has consequently increased. In other words, some facilities have experienced energy efficiency decline during the pandemic. One possible reason is that some primary energy systems are not designed for such low production rates, and the turndown ratio is too low to accommodate such production rates.

Additionally, manufacturing facilities have been implementing practices to maximize the physical distance between workers and reduce workers' exposure to COVID-19. Many of these practices negatively impacted energy efficiency, such as fewer people but longer shifts, increasing outdoor air intake, installing higher efficiency air filters, and adding ultraviolet germicidal irradiation lamps in air streams.

\subsubsection{Solution 1: Improve Shutdown Procedures}

Through about 25 energy treasure hunt INPLTs, the BP Program learned that many sites keep a few energy support systems and equipment unnecessarily running during the weekend shutdowns. Improved shutdown procedures can save energy by shutting down equipment that are left on and by identifying and fixing malfunctioning equipment (e.g., leaking water and compressed air control valves) during shutdowns of various lengths.

For example, General Motors was able to reduce the energy consumption by $90 \%-95 \%$ during 3 -hour, weekend, and multiweek shutdowns by performing energy trend data analysis and site surveys to identify unnecessary running equipment. 


\subsubsection{Solution 2: Reduce Baseload Energy}

Baseload energy is the energy consumption that does not vary with production outputs (Figure 3). Baseload energy occurs when some types of equipment are required to run at full capacity for 24/7 and the capacities of some equipment cannot be modulated to match process loads due to inadequate control schemes or unsophisticated controls. Some examples are lighting in areas where maintenance personnel are present after work shifts, compressed air demand to maintain seals on lift station pumps, and HVAC systems that maintain building setback temperature. There will always be some baseload, but the intent is to minimize it.

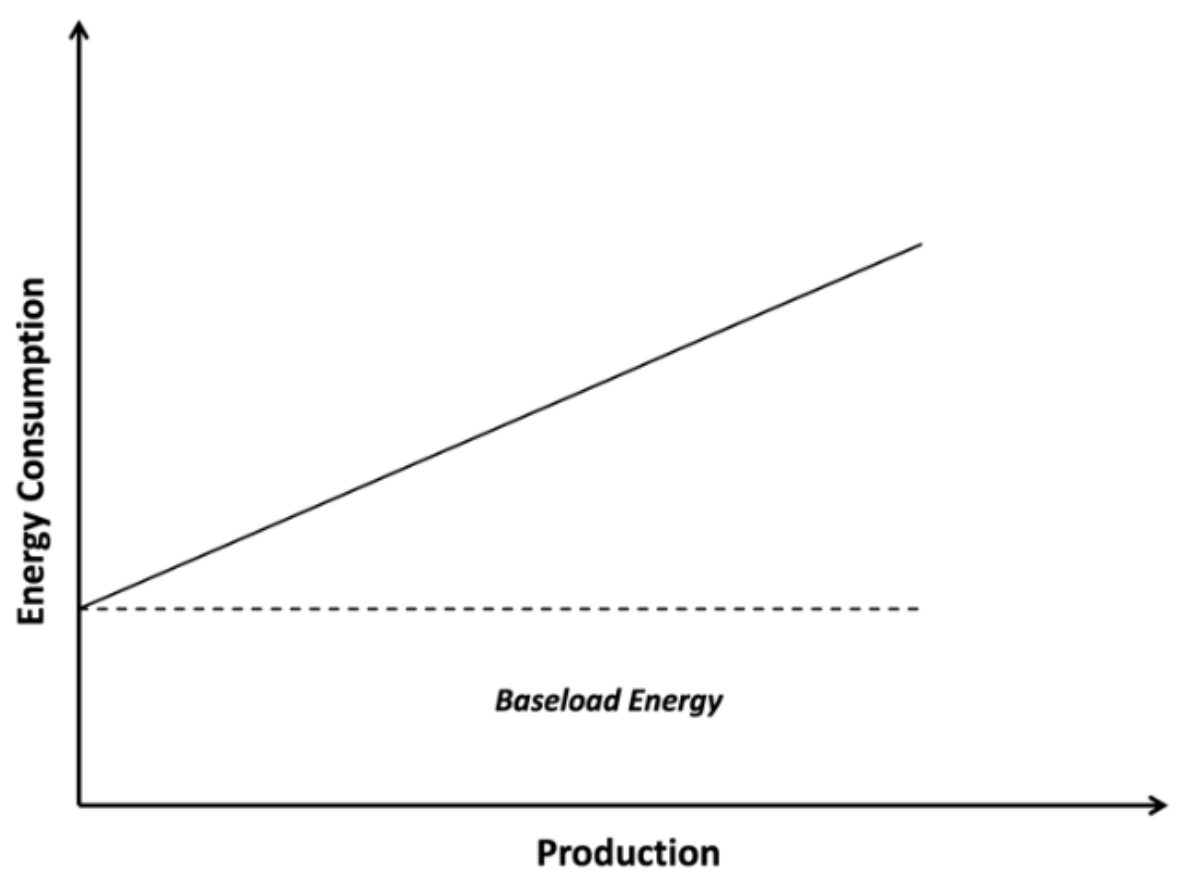

Figure 3. Baseload Energy.

For example, Quad Graphics developed resources to perform a baseload energy demand survey, analyze energy consumption trends, and quantify savings from proposed solutions. Standard operating procedures have been developed to ensure that employees clearly understand which equipment can or cannot be powered down. One plant achieved a baseload energy reduction of $28 \%$ and $\$ 375$ annual energy cost savings per baseload survey hour. Most plants have reported more than \$200 annual energy cost savings per baseload survey hour [10].

\subsection{LIMITED ACCESS TO ENERGY SYSTEMS}

To minimize the number of people working within facilities and maximize the physical distance between workers, only the minimum facility engineers are allowed into plants to ensure the proper operation of energy systems. Other facility engineers are required to work from home part or full time. Corporate engineering teams are not allowed to travel to support individual sites. Vendors and contractors cannot enter facilities unless their business is essential.

Furthermore, many manufacturing facilities do not have the capability to remotely monitor and adjust equipment operations. This presents a great challenge for engineers who are not allowed into the facilities to help identify energy-savings opportunities and make corresponding adjustments. 


\subsubsection{Solution 1: Create an Effective Online Energy-Monitoring System}

An effective online energy-monitoring system collects data from various meters and sensors and provides engineers with insights into the real-time energy consumption and operation status of all primary industrial systems. By analyzing more granular system energy and operational data, engineers can identify and implement less obvious and more sophisticated energy conservation projects. The online energy-monitoring system also allows engineers to remotely adjust system operation to achieve the desired energy performance. This is particularly important when engineers cannot physically access the facility during pandemics and natural disasters, and it also reduces companies' future travel costs.

It might not be economical to install submeters for each piece of energy-using equipment within industrial systems. However, if enough meters and sensors can be installed so that the monitored total energy consumption can mimic the site's actual energy curve, then the energy performance of major industrial systems can be evaluated.

For example, Saint-Gobain installed wireless submeters that capture $75 \%$ of a facility's electrical usage. By using more granular energy data, one Saint-Gobain plant reduced electrical energy intensity (MWh per unit of product) by 14\% from 2016 to 2017 by optimizing the operation of dryers, compressors, blowers, and other equipment [11].

The online energy-monitoring systems have enabled facility engineers at General Motors to monitor and adjust the operation of major equipment at all sites from home during the pandemic and other shutdowns. Thanks to real-time operational data and convenient remote equipment access, General Motors has successfully performed a few virtual energy treasure hunts during the pandemic [12].

\subsubsection{Solution 2: Deploy Automatic Predictive Maintenance Technologies}

By using advanced sensors and data analysis technologies and decision-making algorithms, predictive maintenance technologies automatically adjust equipment operations and maximize their energy performance without human interference.

For example, an advanced combustion control system includes air and fuel control valves, mass flow meters, oxygen sensors in the exhaust stack, and a decisions-making controller (Figure 4). This system continuously monitors the oxygen concentration in the exhaust and automatically adjusts the air-to-fuel mass rate ratio accordingly to maintain near-optimum combustion efficiency. Unlike mechanical linkage controls, this technology does not need frequent calibrations and can achieve much higher energy efficiency [13]. 


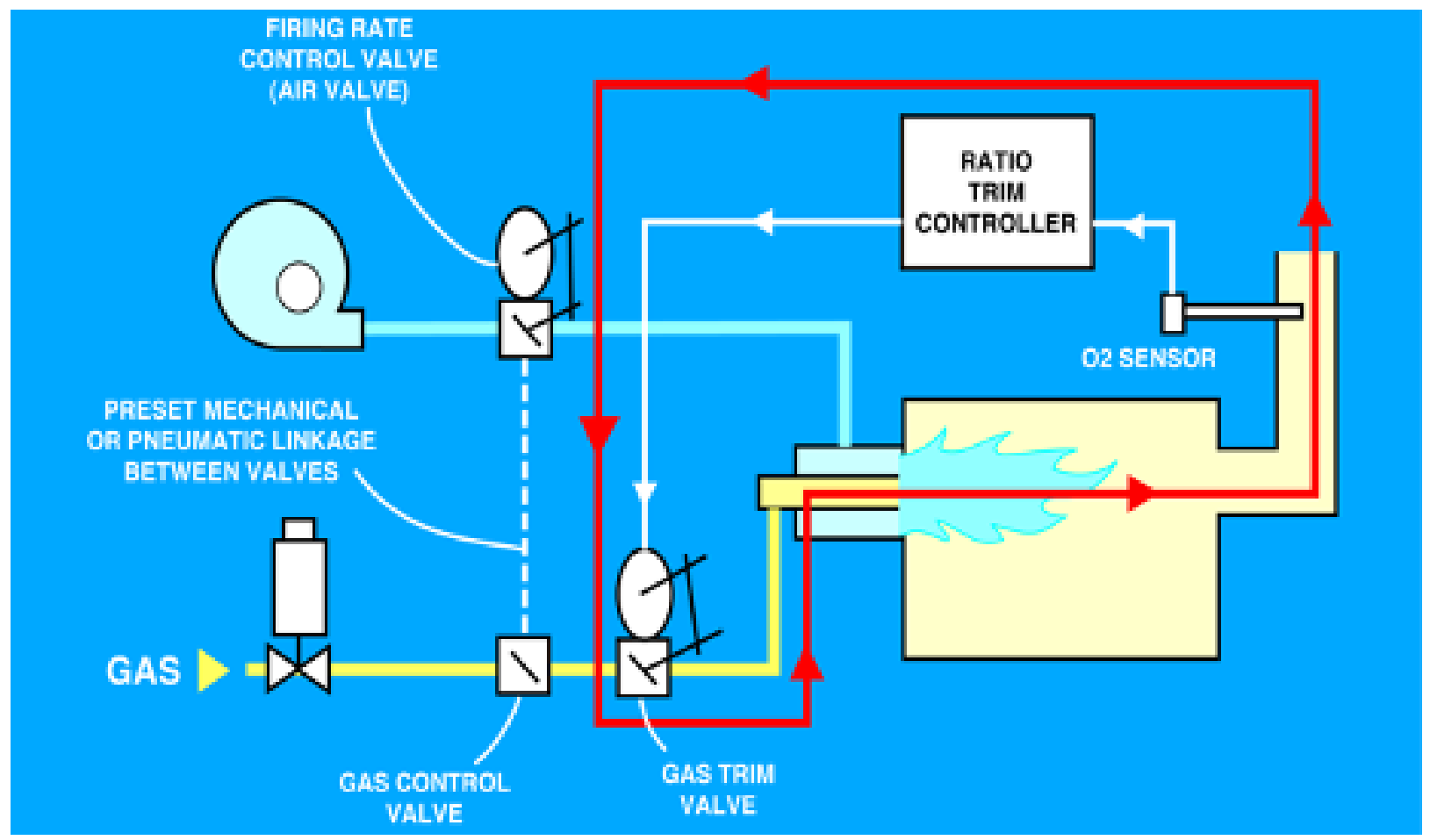

Figure 4. Advanced Air-to-Fuel Ratio Controls [14].

\subsubsection{Solution 3: Perform Virtual Energy Assessments}

A traditional energy assessment involves a facility energy trend data analysis and an in-person inspection of the operation settings and status of major industrial systems to identify energy conservation opportunities. A virtual energy assessment primarily relies on the on-site team to walk through the facilities and collect data related to equipment settings and operational status. External experts remotely facilitate the process, address questions from local teams, and provide technical support.

An online energy-monitoring system can give external experts remote access to equipment and makes the communications between external experts and on-site teams more effective. For companies without it, each on-site team needs at least one experienced engineer who has good knowledge of the facility and knows how to collect equipment operation data. To maximize social distancing, companies can perform a thorough pre-assessment data analysis and form a small but competent team to focus on only a few systems with the most energy-savings potential.

The BP Program is looking to provide virtual INPLT's for energy treasure hunts and various energy systems in late 2020. Partners will receive updates on it soon.

\subsection{LOST KNOWLEDGE AND EXPERIENCE OF SENIOR STAFF}

According to the recent Clean Jobs America report [15], US energy efficiency workers filed for nearly 70,000 unemployment claims in March 2020. Some companies have offered early retirement packages to senior staff members to alleviate financial stress, which resulted in the loss of their knowledge of and experience with the equipment and systems. The lost knowledge and experience could have a negative impact on improving and maintaining the facility energy performance unless operation procedures for these equipment and systems are well documented and other personnel are well trained on energy efficiency. 


\subsubsection{Solution 1: Build a Robust Energy-Management System}

A robust energy-management system (EnMS) helps companies integrate energy management into everyday business practices and provides a systematic approach for improving and maintaining the energy performance of their facilities. An effective EnMS documents all important facility operation procedures and system playbooks to formalize knowledge sharing and ensure smooth team transitions.

The 50001 Ready Navigator is a free online tool developed by DOE that provides self-paced, step-by-step guidance for implementing and maintaining an EnMS [16]. While 50001 Ready Navigator does not explicitly utilize the Plan-Do-Check-Act ISO structure, the Navigator has 25 tasks that align with the requirements specified in the ISO 50001 Energy Management System Standard [17]. Each task within the Navigator has many resources to facilitate users to implement. Figure 5 shows the energy management system model for ISO 50001. Companies can use Navigator to build an EnMS from scratch and prepare facilities for ISO 50001 and Superior Energy Performance 50001 ${ }^{\mathrm{TM}}$ certification.

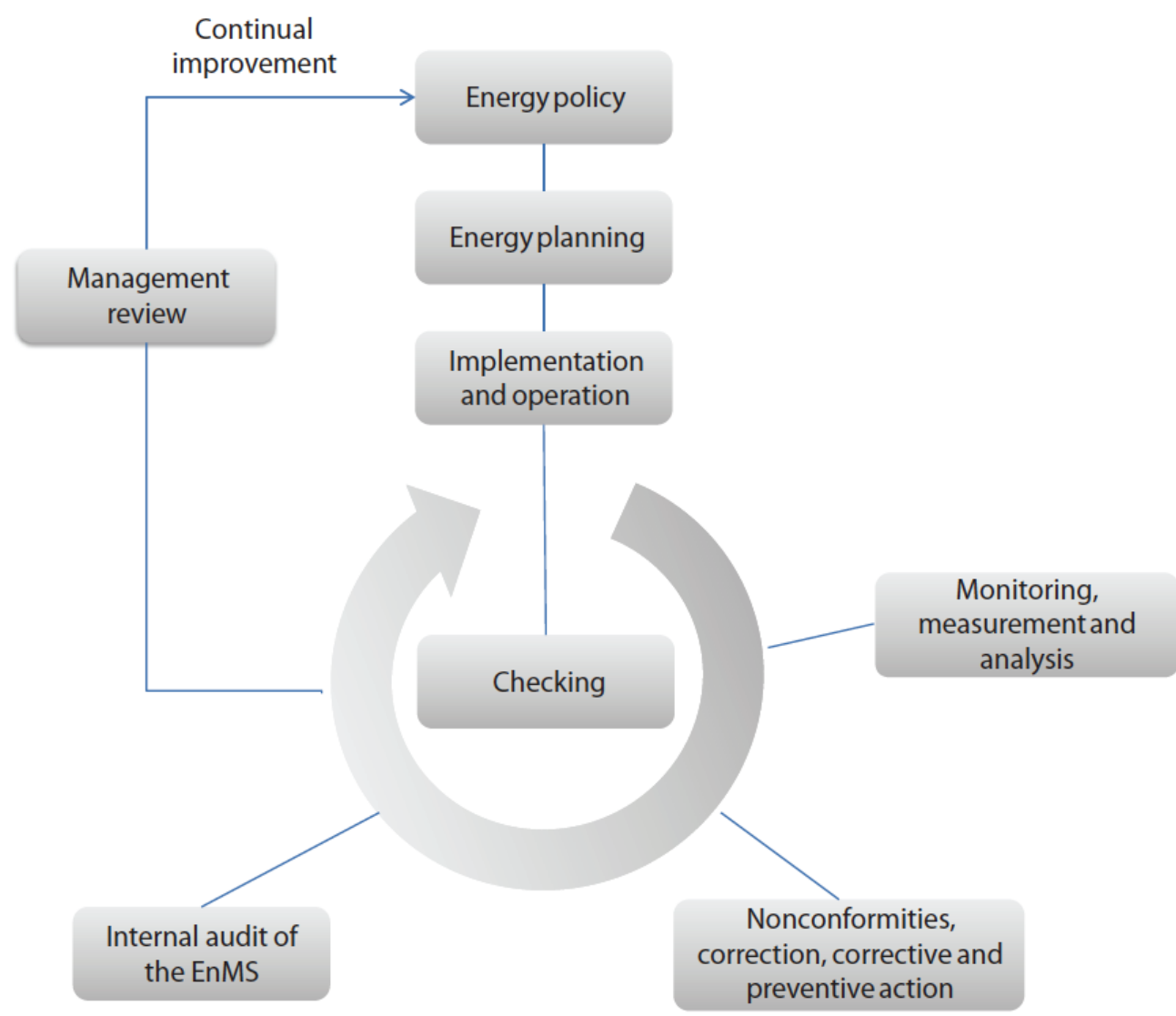

Figure 5. Energy Management System Model for ISO50001 [17].

\subsubsection{Solution 2: Attend Training Events}

Although many companies are working toward settling into the new normal, they should continue to train their energy management team, equipment operators, and other employees on energy-management knowledge, resources, and best practices through online learning. For example, companies can take advantage of readily available online resources created by DOE (e.g., Better Buildings webinar series [18], BP online learning series [19]) and the US Environmental Protection Agency (e.g., ENERGY STAR webinars [20]). 
The BP Program provides INPLTs to help partners enhance in-house energy efficiency expertise [21]. All INPLTs are led by industry-recognized subject matter experts. In addition to informative in-class lectures, INPLTs provide hands-on experience for major industrial systems (e.g., pumping, fan, compressed air, steam, process heating) in real-world manufacturing settings. INPLT applications are free and open to all BP partners. The Fundamentals of Energy Management Training, a new course designed to help new energy managers understand the industrial energy landscape, will be provided by the BP Program in the future.

\section{SUMMARY}

The COVID-19 pandemic is causing many challenges for manufacturers, especially those that depend on workers whose jobs cannot be performed remotely. This has detrimentally impacted the energy management workforce, energy support system performance, as well as operations and supply chains. This article discusses four primary challenges for industrial energy management caused by the pandemic, strained budget for energy projects, increased energy intensity caused by low production rates and other safety practices, limited access to energy systems, and the lost knowledge and experience of senior staff.

This article also proposes some potential solutions for these challenges that include implementing no- and low-cost energy conservation measures, adopting alternative financing options, improving shutdown procedures, reducing baseloads, creating an effective online energy-monitoring system, performing virtual energy assessments, building a robust EnMS, and attending online and in-person training events.

\section{REFERENCES}

1. National Association of Manufacturers, Manufacturers' Survey Reveals Current Industry Impact of COVID-19, (2020). https://www.nam.org/manufacturers-survey-reveals-current-industry-impact-ofcovid-19-7411/.

2. US DOE AMO, MEASUR, (2020). https://www.energy.gov/eere/amo/measur.

3. US DOE AMO, Energy Treasure Hunt Exchange Toolkit, (2020). https://betterbuildingssolutioncenter.energy.gov/energy-treasure-hunt-exchange-toolkit.

4. US DOE AMO, Tip Sheets by System, (2020). https://www.energy.gov/eere/amo/tip-sheets-system.

5. Compressed Air Challenge, US DOE, AMO, Improving Compressed Air System Performance: A Sourcebook for Industry, (2003).

6. W. Guo, T. Wenning, K. Thirumaran, S. Nimbalkar, and E. Levine. 2019 US DOE Better Plants Program Energy Treasure Hunt Exchange Toolkit. United States Department of Energy.

Doi:10.2172/1493120. https://www.osti.gov/biblio/1493120-us-doe-better-plants-program-energytreasure-hunt-exchange-toolkit

7. US DOE Better Buildings Program, Better Buildings Financing Navigator, (2020). https://betterbuildingssolutioncenter.energy.gov/financing-navigator/explore.

8. US DOE Better Buildings Program, Better Buildings Financial Allies, (2020). https://betterbuildingssolutioncenter.energy.gov/financing-navigator/allies.

9. US DOE AMO, Bentley Mills: Reducing Risk and Liability in Energy Upgrades Through Efficiency. As-A-Service Financing (EaaS), (2019).

https://betterbuildingssolutioncenter.energy.gov/implementation-models/bentley-mills-reducing-riskand-liability-energy-upgrades-through-efficiency-a 
10. T. Wenning, W. Guo, S. Nimbalkar, E. Levine, Innovative Energy Management Strategies and Solutions - What We Have Learned from Leaders, in: 2019 ACEEE Summer Study on Energy Efficiency in Industry, Portland, OR, 2019.

11. US DOE Better Buildings Program, Saint-Gobain Corporation: Advanced Energy Monitoring with Wireless Submetering, (2019). https://betterbuildingssolutioncenter.energy.gov/showcaseprojects/saint-gobain-corporation-advanced-energy-monitoring-wireless-submetering

12. US EPA, Energy Treasure Hunts During Covid-19, (2020). https://www.energystar.gov/buildings/tools0and-resources/energy treasure hunts during covid 19

13. S. Nimbalkar, W. Guo, A. Carpenter, J. Cresko, D.J. Graziano, W. Morrow, T. Wenning, Smart Manufacturing Technologies and Data Analytics for Improving Energy Efficiency in Industrial Energy Systems, in: 2017 ACEEE Summer Study on Energy Efficiency in Industry, Denver, CO, 2017.

14. US DOE AMO. 2015. Energy Efficiency Improvement for Process Heating Equipment, Workshop on Industrial Process Heating Systems - Qualified Specialist Training.

15. 2E (Environmental Entrepreneurs), Clean Jobs America 2020 - Repowering America's Economy in the Wake of COVID-19, 2020.

16. US DOE AMO. 50001 Ready Navigator. https://navigator.lbl.gov

17. International Organization for Standardization. 2011. ISO 50001: Energy Management Systems Requirements with Guidance for Use.

18. US DOE Better Buildings Program, Better Buildings Webinars, (2020). https://betterbuildingssolutioncenter.energy.gov/webinar-list.

19. US DOE Better Buildings Program, Better Plants Online Learning Series, (2020). https://betterbuildingssolutioncenter.energy.gov/better-plants/online-learning-series.

20. US EPA, ENERGY STAR Webinars, (2020). https://esbuildings.webex.com/mw3300/mywebex/default.do?siteurl=esbuildings.

21. W. Guo, T. Wenning, S. Nimbalkar, J. Travis, E. Levine, US DOE In-Plant Trainings to Develop Expertise and Replicate Success, in: 2019 ACEEE Summer Study on Energy Efficiency in Industry, Portland, OR, 2019. 